\title{
Anatomical description of double left suprarenal vein and its implications on renal transplantation surgeries
}

\author{
ASSIS, T. O. ${ }^{*}$, FERNANDES, L. S. ${ }^{2}$ and ARAÚJO FILHO, J. C. ${ }^{3}$ \\ ${ }^{1}$ Department of Morphology, Federal University of Paraíba - UFPB, Cidade Universitária, \\ CEP 58051-900, Castelo Branco, João Pessoa, PB, Brazil \\ ${ }^{2}$ Department of Biology, University of Paraíba - UEPB, Rua Baraúnas, 351, CEP 58429-500, \\ Bairro Universitário, Campina Grande, PB, Brazil \\ ${ }^{3}$ Department of Physiotherapy, Federal University of Pernambuco - UFPE, Professor Moraes Rego, \\ 1235, CEP 50670-901, Cidade Universitária, Recife, PE, Brazil \\ *E-mail: thiago.oa@hotmail.com
}

\begin{abstract}
Introduction: Left suprarenal vein (LSRV) is a tributary of the left renal vein in more than $95 \%$ of the population. In a research carried out by Mas, Arango, Guzmán et al. (1987), the double suprarenal vein appeared on $2.7 \%$ of the 110 nephrectomies done. The suprarenal vein (SRV) was unique on the 34 bodies analyzed by Duques, Rodrigues, Silva Neto et al. (2002). Therefore, the anatomical variations of the LSRV are rare, but its study is a subject of clinic and surgical importance for renal transplants. The objective of this study was to describe the dissection of the double LSRV. Material and Methods: A caliper rule was used to measure the length of the studied veins. The dissection of the left kidney and adrenal was done according to standard technique. Results: The different origins and trajectories of the double LSRV (normal and variant), tributaries and left renal vein were verified. The normal LSRV measured $3 \mathrm{~cm}$ up to the renal vein whereas the variant SRV, with $7.5 \mathrm{~cm}$ and thinner, went out of the lateral suprarenal border, went down adjacent to the kidney face to end in the left renal vein around $1.8 \mathrm{~cm}$ distal to the first. Conclusions: The variant SRV showed double the normal length, lower diameter and difficult visualization in situ because of its trajectory between the superior pole of the kidney and the suprarenal anterior face. This trajectory evokes extra care during surgical procedures of renal transplantation, mostly to avoid hypotension and hypovolemia after SRV ligation.
\end{abstract}

Keywords: double left suprarenal vein; kidney transplantation; anatomical variation

\section{Introduction}

The suprarenal glands are in pair, retroperitoneal, bilateral and located on the medial part of the superior pole of the kidney. They are irrigated by three arterial pedicles: (1) superior suprarenal arteries, originated from the phrenic arteries, (2) middle suprarenal arteries, originated directly from the aorta and (3) inferior suprarenal arteries, originated from the adjacent renal artery (DÂNGELO and FATTINI, 2007). Differently, the venous drainage of each gland is done by one unique vein. This way, the right suprarenal vein (RSRV), which is very short, drains the blood to the inferior vena cava, whereas the left suprarenal vein (LSRV) generally unites with the inferior phrenic vein to drain the blood to the left renal vein (LRV) and consequently to the inferior vena cava (MOORE and DALLEY, 2005; DÂNGELO and FATTINI, 2007). The left renal vein is bigger than the right one, what determines the preference of selecting the left kidney for renal transplantations (DUQUES, RODRIGUES, SILVA NETO et al., 2002).

Studying the LSRV and its variants is anatomically and clinically important and important to the kidney transplantations too. On those not only the normal anatomic structures must be taken into consideration but knowing, identifying and intervening on anatomical variations has also to be considered. According to Costa, Moreira, Fukunaga et al. (2011) the number of nephrectomies for kidney transplantations has increased due to an increase in the number of dead donors and such anatomical variations, if not recognized, might complicate the procedure or even compromise the viability of the donated kidney.

The objective of this study was to describe the dissection of the double LSRV and correlate with the clinical data of kidney transplantation.

\section{Methods}

It is an observational study of dissection. It was done on a female body from the anatomy laboratory of the University of the State of Paraíba (Campus 1). Through standard technique, the organs from the anterior abdominal space were taken out, the retroperitoneal viscera exposed, and the double LSRV trajectory was described. Later on, the kidney, the renal vein, the suprarenal gland and the double LSRV were dissected (also by standard technique) for evaluation. A Mitutoyo ${ }^{\circledR}$ digital caliper rule $(150 \mathrm{~mm})$ was used to measure the length of the normal and the variant LSRV, as well as the distance between the left renal vein ending points.

\section{Results and Discussion}

The dissection of the left kidney and the left adrenal gland was done according to standard technique (Figure 1). The different origins and the descendent trajectories of 


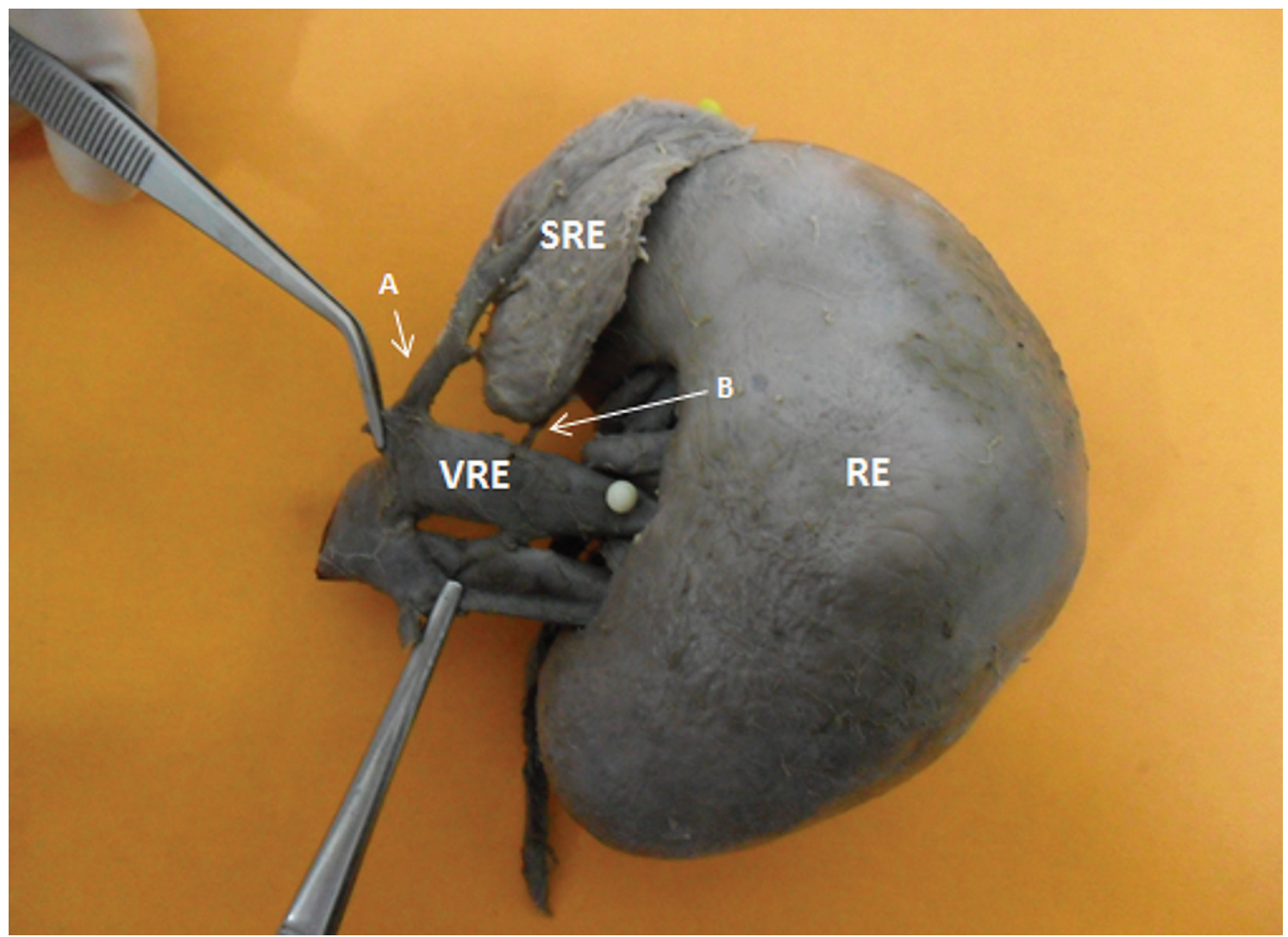

Figure 1. Anterior view of the left kidney (LK), left renal vein (LRV), left renal hilum, normal (A) and variant (B) left suprarenal vein. Source: our data.

the double LSRV (normal and variant) were identified, both tributaries from the left renal vein. The normal LSRV measured $3 \mathrm{~cm}$ up to the renal vein whereas the variant LSRV was $7.5 \mathrm{~cm}$ long. The latter was also thinner, started on the lateral border of the suprarenal and went down adjacent to the renal face to end in the left renal vein, around $1.8 \mathrm{~cm}$ distal of the first. The variant LSRV was two times lengthier than the normal one and was hard to observe in situ due to its trajectory between the kidney upper pole and the renal face of the suprarenal gland.

The LSRV receives the blood from the left suprarenal gland and takes it to the left renal vein. On Figure 1 it is possible to observe that both (normal and variant) LSRV drain into the renal vein. It is an anatomical variation somewhat different from reported on the studies of Mas, Arango, Guzmán et al. (1987), who saw double LSRV in 2.75 of the 78 nephrectomies done on left kidneys for renal transplantation. Duques, Rodrigues, Silva Neto et al. (2002) dissected 34 bodies and did not find variations of the LSRV. On the studies of Costa, Moreira, Fukunaga et al. (2011) no variations of the LSRV were verified, although 4 cases amongst 254 bodies showed duplication of the LRV. On the studies of Ozturk, Uzmansel, Kara et al. (2010) there was one 57-year-old female body with double LSRV, which presented other variations associated with the kidney and the left suprarenal gland vascularization and venous drainage.

Variations of the structure and function of the kidney and the hilum blood vessels are frequently reported (PATIL, MESHRAM and KASOTE, 2011), but suprarenal vessels variations are rare, thus poorly reported on literature. In the laparoscopic surgery, it is important to look for anatomical variations of the suprarenal vein in order to limit the risk of intra-operative hemorrhage during the introduction of the laparoscope (OZTURK, UZMANSEL, KARA et al., 2010), what could compromise the success of the surgical procedure.

\section{Conclusion}

The renal anatomical variations require more attention on the dissection of the hilum in order to avoid a lesion that could compromise the graft. Therefore, the LRV tributaries and variations must be taken into consideration as they could affect the orientation of the surgeon during the laparoscopic adrenalectomy, as well as in the renal transplantations processes.

\section{Referências}

COSTA, HC., MOREIRA, RJ., FUKUNAGA, P., FERNANDES, RC., BONI, RC. and MATOS, AC. Anatomic variations invascular and collecting systems of kidneys from deceased donors. Transplantation Proceedings, 2011, vol. 43, n. 1, p. 61-63. Available from: <http:// www.ncbi.nlm.nih.gov/pubmed/21335155>. PMid:21335155. http://dx.doi.org/10.1016/j.transproceed.2010.12.013

DÂNGELO, JG. and FATTINI, CA. Anatomia humana sistêmica e segmentar. 3. ed. São Paulo: Atheneu, 2007. 
DUQUES, P., RODRIGUES, JR., SILVA NETO, FB., NETO, EMVS. and TOLÊDO, ES. Estudo anatômico da veia renal esquerda de cadáveres humanos brasileiros. Medicina, 2002, vol. 35 , p. 184-191.

MAS, AG., ARANGO, O., GUZMÁN, A., CORONADO, J., ROSALES, A., CORTADELLAS, R. and BALLESTEROS, JJ. Anatomia hilar venosa renal. A propósito de 110 nefrectomias para transplante renal. Actas Urolológica Españolas, 1987, vol. 11, p. $172-175$.

MOORE, KL. and DALLEY, KL. Anatomia orientada para a clínica. 5. ed. Rio de Janeiro: Guanabara Koogan, 2005.
PATIL, ST., MESHRAM, MM. and KASOTE, AP. Bilateral malrotation and lobulation of kidney with altered hilar anatomy: a rare congenital variation. Surgical and Radiologic Anatomy, 2011, vol. 33, n. 10, p. 941-944. Available from: <http://www.ncbi.nlm. nih.gov/pubmed/21626276>. PMid:21626276. http://dx.doi. org/10.1007/s00276-011-0826-6

OZTURK, NC., UZMANSEL, D., KARA, A. and OZTURK, H. Variation in the position, relation and vasculature of left suprarenal gland: a case report. Surgical and Radiologic Anatomy, 2010, vol. 32, n. 10, p. 985-988. Available from: <http://www.ncbi.nlm. nih.gov/pubmed/20162417>. PMid:20162417. http://dx.doi. org/10.1007/s00276-010-0636-2

Received November 27, 2013

Accepted November 28, 2014 